\title{
Is South African Manufacturing SMMEs Ready for the Fourth Industrial Revolution?
}

\author{
Lizzie L. Mabotja \\ Small Enterprise Development Agency (SEDA), South Africa \\ lmabotja@seda.gov.za,627tebatso@gmail.com
}

\begin{abstract}
The fourth industrial revolution is unquestionably resulting in significant changes in the workforce landscape, technological advancements, industry relations and it affects all aspects of society and the economy. This research paper is based on results from an earlier study focused on the challenges faced by small, medium and micro enterprises (SMMEs), sharing results from survey data and in-depth interview analyses conducted. A sample of 66 SMMEs was selected purposefully from the Small Enterprise Development Agency (SEDA)'s database where manufacturing SMMEs alluded to some of the critical challenges they are facing. A key finding from the research was that technological advancement and digital manufacturing are significant challenges for manufacturing SMMEs in South Africa. Small businesses are critical to South Africa's ability to participate profitably in the fourth industrial revolution. The research shows that there are significant challenges for manufacturing SMMEs and that should be urgently addressed if South Africa is to participate advantageously in the fourth industrial revolution. This study recommends embedding technology into education and embracing new advancements and machinery within the education system. A change in the education system will help create a supply for future skills needed in the manufacturing sector. Manufacturing SMMEs contribute to a stronger economy and should embrace automation and artificial intelligence; this requires determined and collaborative efforts from government, its agencies and private sector through broader information sharing, planning for future skills and a dedicated fund for technology and modern machinery funding across various industries, particularly manufacturing.
\end{abstract}

Keywords: SMMEs, Challenges, Manufacturing Sector, Entrepreneurship, Industrial Revolution.

\section{Introduction}

The fourth industrial revolution is not only a fashionable buzz word but an ongoing shift in the future of manufacturing and will completely change the global business environment Cohen, (2018). The fourth industrial revolution is unquestionably already resulting in significant changes in the workforce landscape, technological advancements, industry relations and it affects all aspects of society and the economy. This research paper focuses on the readiness of the South African manufacturing SMMEs sector to fully participate in the fourth industrial revolution and take advantages of the opportunities that come with it.

Background: It is widely agreed upon by policymakers and researchers alike that the manufacturing sector contributes positively to the economic performance and competitiveness of a country Seda, (2012). A strong and globally competitive manufacturing sector is desirable, and a path towards growth and development. "Manufacturing is essential for long term economic growth and economic resilience. However, many of its characteristics are changing profoundly. Physical production processes are increasingly at the centre of much wider value chains" Foresight, (2013). Similarly small, medium and micro-enterprises (SMMEs) are the bedrock of most economies, particularly in developing countries. However, they need to adapt in both product and production to stay competitive Issa et al. (2017). According to Nieman, (2006) SMMEs have become an essential focus of policymaker. Due to their labour-absorptive capacity as growing businesses, their ability to adapt rapidly to changing preferences and trends and their support for local industries by sourcing their resources locally and provides suitable opportunity young entrepreneurs and play a vital role in technical and other innovation. This study will specifically focus on manufacturing SMMEs, based on their importance to economic growth, it is essential to understand if they will see Industry 4.0 as an obstacle or as an opportunity.

\section{Review of Literature}

Definition and Importance of Small Medium and Micro Enterprises (SMMEs): There is not one agreed upon definition of SMMEs that is used globally, in fact, there are many inconsistencies in how SMMEs are defined across the world Small-Medium. The definition covers survivalists, micro, very small, small and 
medium-sized enterprises. SMMEs are defined either according to their turnover, value or assets or most commonly but the number of employees according to sector or industry. Microenterprises are those with fewer than five employees, 'small businesses have 6 to 20, small businesses have 21 to 50, and medium businesses have fewer than 200 employees. In SA, a 'small business' is officially defined in Section 1 of the National Small Business Act of 1996 as amended by the National Small Business Amendment Acts of 2003 and 2004 (NSB Act) as:

"... a separate and distinct business entity, including co-operative enterprises and nongovernmental organisations, managed by one owner or more which, including its branches or subsidiaries, if any, is predominantly carried on in any sector or sub-sector of the economy..."

SMMEs in South Africa play an essential role in the growth of the economy. They are drivers of economic growth, innovation and job creation. These enterprises contribute significantly to national GDP and have proved to be significant contributors to job creation (The DTI, 2008). The current unemployment rate in South Africa sits at a high 27.1\% (StatsSA, 2017). In South Africa, the government recognizes the importance of this segment of business activity, so much so that a Ministry of Small Business Development was established in early 2014. The ministry is supported by agencies such as Small Enterprise Development Agency (Seda), Small Enterprise Finance Agency (SEFA), The National Youth Development Agency (NYDA) Technology and Innovation Agency (TIA). National Empowerment Fund (NEF), all of which play a different role in working towards the ministry's SMME strategy of increasing financial and non-financial support for SMMEs, creating a demand for the product and services provided by SMMEs and reducing regulatory constraints (BER, 2016).

Definition of the Fourth Industrial Revolution: The fourth industrial revolution or industry 4.0 is a term that was first used by the founder and executive chairman of the World Economic Forum, Klaus Schwab. According to Schwab (2015:1), we are at "the brink of a technological revolution that will drastically alter how we live, work and relate to one another." The Fourth Industrial Revolution has been taking place since the beginning of the $21^{\text {st }}$ century. It is a worldwide shift in the mobile Internet, cheaper, smaller and stronger sensors and artificial and machine learning Lee, et al. (2018). It was the fourth major industrial era since the first industrialisation in the $18^{\text {th }}$ century. A key distinguishing factor that warrants regarding it as a revolution is its speed, universal scope and systems impact; and it has no historical precedent, and it comes with changes that cut across all production and management systems. It introduces digitisation and the fusion of technologies blurring the lines between the physical, digital and biological spheres of global production Schwab (2015), Kearney, (2017), and Xu, et al. (2018). According to Lu, (2017) in Slusarczy, (2018) the concept of Industry 4.0 can be summarised as "an integrated, adapted, optimised, service-oriented, and interoperable manufacturing process which is correlated with algorithms, big data, and high importance."

Another definition from Lu, (2017) says the "Industry 4.0 describes the increasing digitisation and automation of the manufacturing environment, as well as the creation of digital value chains to enable communication between products, their user environment and business partners". These definitions emphasise the widespread change and recognise that manufacturing as we know it will change entirely towards automation. The Fourth Industrial Revolution on Manufacturing SMMEs: In his opening address at the South African President Cyril Ramaphosa places youth, women and SMMEs at the centre of the Fourth Industrial Revolution. Africa News Agency, (2018). How business is conducted has involved technology since the $21^{\text {st }}$ century; business operations are on the internet they use large amounts of data, advanced machinery, smart computers etcetera. These technologies can assist SMMEs to reach a broader market and reduce their production costs. This section of the paper briefly addresses the impact that the Fourth Industrial Revolution had on manufacturing SMMEs. To this end, both the quantitative and qualitative research methods were adopted for this research.

Overview and Performance of South Africa's Manufacturing Sector: After suffering a continuous decline following the significant contraction caused during the international financial crisis of 2008/9; the South African manufacturing sector, it has recently bounced back in 2018 recording the highest annual growth rate in five years. According to the latest Manufacturing: Production and sales release from Statistics South Africa, showing a production increased by $1,2 \%$ which pulled the country out of recession in the third quarter of 2018, this is shown in Figure 1 below, Statistics South Africa, (2019). 
Figure 1: Manufacturing Production and Sales, December 2018, Statistics South Africa

\section{Manufacturing production climbed by 1,2\% in 2018}

Annual percentage change in the volume of manufacturing production

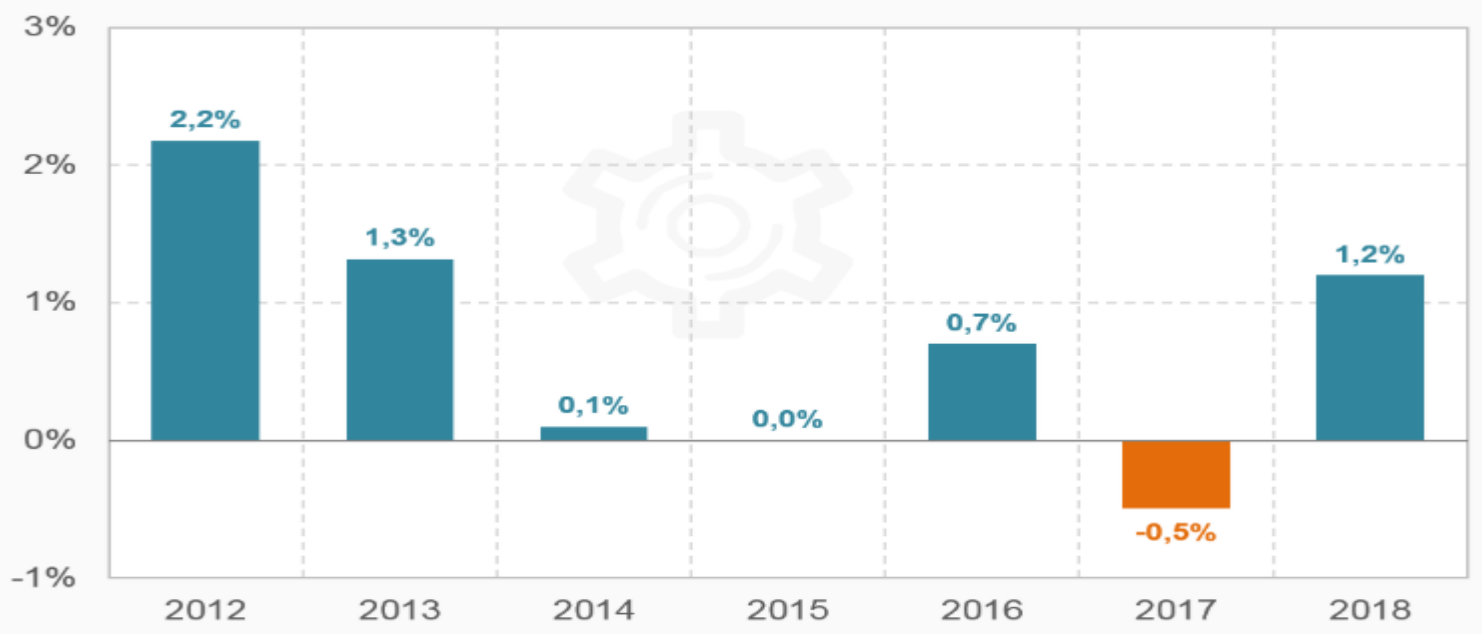

This report from Statistics South Africa maintains that the manufacturing sector is the country's fourth largest industry, contributing $14 \%$ to the country's gross domestic product (GDP). The manufacturing industry strong potential to grow the economy and creates employment. Efforts to develop this sector and prepare it for the Fourth Industrial Revolution will yield rewards that growth the sector's employment and its global competitiveness and inject growth into other sectors such as agriculture, Wholesale and retail trade and Services.

\section{Methodology}

This research paper focuses on the readiness of the South African manufacturing SMMEs sector to fully participate in the fourth industrial revolution and take advantages of the opportunities that come with it. The research method selected intends to gain an in-depth understanding of the manufacturing SMMEs' perspectives on the fourth industrial revolution and their ability benefit from it. The manufacturing SMME population used was from Seda's client database. Purposive sampling was applied to a population of active Seda clients in the manufacturing sector from for the financial years 2016/17 and 2017/18 in Seda's Clients Relationship Management (CRM) database. A semi-structured questionnaire, containing 15 questions was distributed electronically to SMME Seda clients in manufacturing; which included an open-ended comments section. A total of 530 Seda clients were sent the survey which was distributed by e-mail. The survey was also live online for 30 days with periodic reminder e-mails were posted every ten days. Parallel to the survey, focus ground discussions were conducted with four manufacturing SMMEs that were readily accessible. Sixtysix completed the questionnaires were received from the e-mail survey, yielding a $12.4 \%$ response rate. The focus ground discussion produced responses from four SMMEs, with a response rate of $4 \%$. The result of the survey is presented in the following section.

\section{Results and Discussion}

A majority of the SMMEs in the study were located in the country's economic hub on South Africa, Gauteng at $27 \%$, closely followed by the coast in Western Cape at $24 \%, 16 \%$ are from Northern Cape. The data was collected from SMMEs in the manufacturing sector, which included sub-sector such as automotive, agroprocessing, food and beverages, metals and machinery and textiles, clothing and footwear. The respondents were mostly start-up with; $61 \%$ of the respondents from the survey have only been in operation for $0-3$ years; $25 \%$ have been in operation for $4-7$ years, $9 \%$ in service for $8-15$ years and $5 \%$ in service for 15 years or more. $73,2 \%$ of the survey respondents make less than R1 million per annum. The overall findings from the study are summarised in the graph below and discussed in detail in the sections that follow. 


\section{Figure 2: Key Challenges of Manufacturing SMMEs, Researcher's Data (2018)}

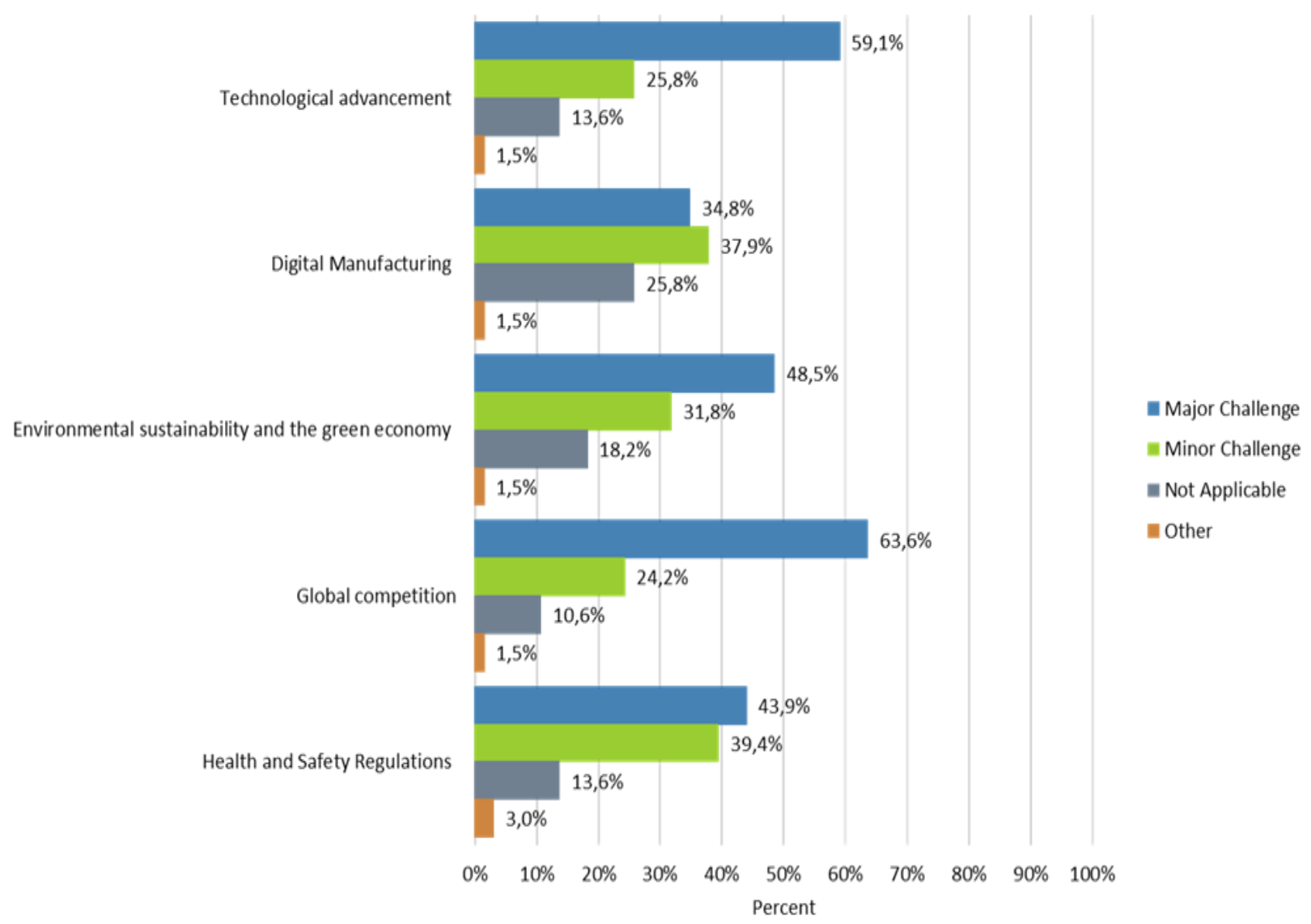

Globalisation and a knowledge-intensive economy resulted in the global competition of skills; South African Manufacturers SMMEs are finding it difficult to retain good talent Evans Distribution Systems (2015). Keeping up with industry 4.0 also comes with the need to train and upskill the workforce on new technology continually, the cost associated with this is difficult to maintain for SMMEs, and they often lose talent to large global manufacturers. South Africa's SMMEs ownership and employment are under pressure the number of SMMEs declined by $1.4 \%$ year on year. The employment is the sector I the same period amounted to $20 \%$. Meaning 8.1 million employees left the sector and more SMMEs failed in this same period Deloitte, (2016), Seda, (2018). The implication is that SMME start-ups (say, enterprises of three years and younger) require special assistance in the current economic climate. The manufacturing sector is at its most dynamic stage, and constant upgrade is the order of the day. The challenge that SMMEs face is lack of funding that results in a lack of innovation. To acquire the latest equipment large capital funds are required and SMMEs reference lack of financing as a deterrent. There has however been a lot of effort from government to assist SMMEs frantically. It must be noted that no matter the amount of funding if an SMME has little or no access to markets, failure is imminent as business success comes through the sale of products or services Mutoko, (2014).

Technological Advancement as a Key Challenge for Manufacturing SMMEs in South Africa: A central aspect of the research was to get an intimate understanding from the perspective of the manufacturing SMMEs' challenges. To this end, the respondents were the key obstacles and priorities are towards the implementation of these business strategies for business success. Error! Reference source not found. Below shows result regarding what a key challenge is currently for these manufacturing SMMEs. This research paper will focus only on the problems of technological advancement and digital manufacturing as they relate to the research question regarding South African manufacturing SMMEs readiness for the Fourth Industrial Revolution. We need current technology machines; we need to access the latest technology"- (Respondent, 2018). 
Figure 3: Technological Advancement as a Major Challenge, Researcher's Data (2018)

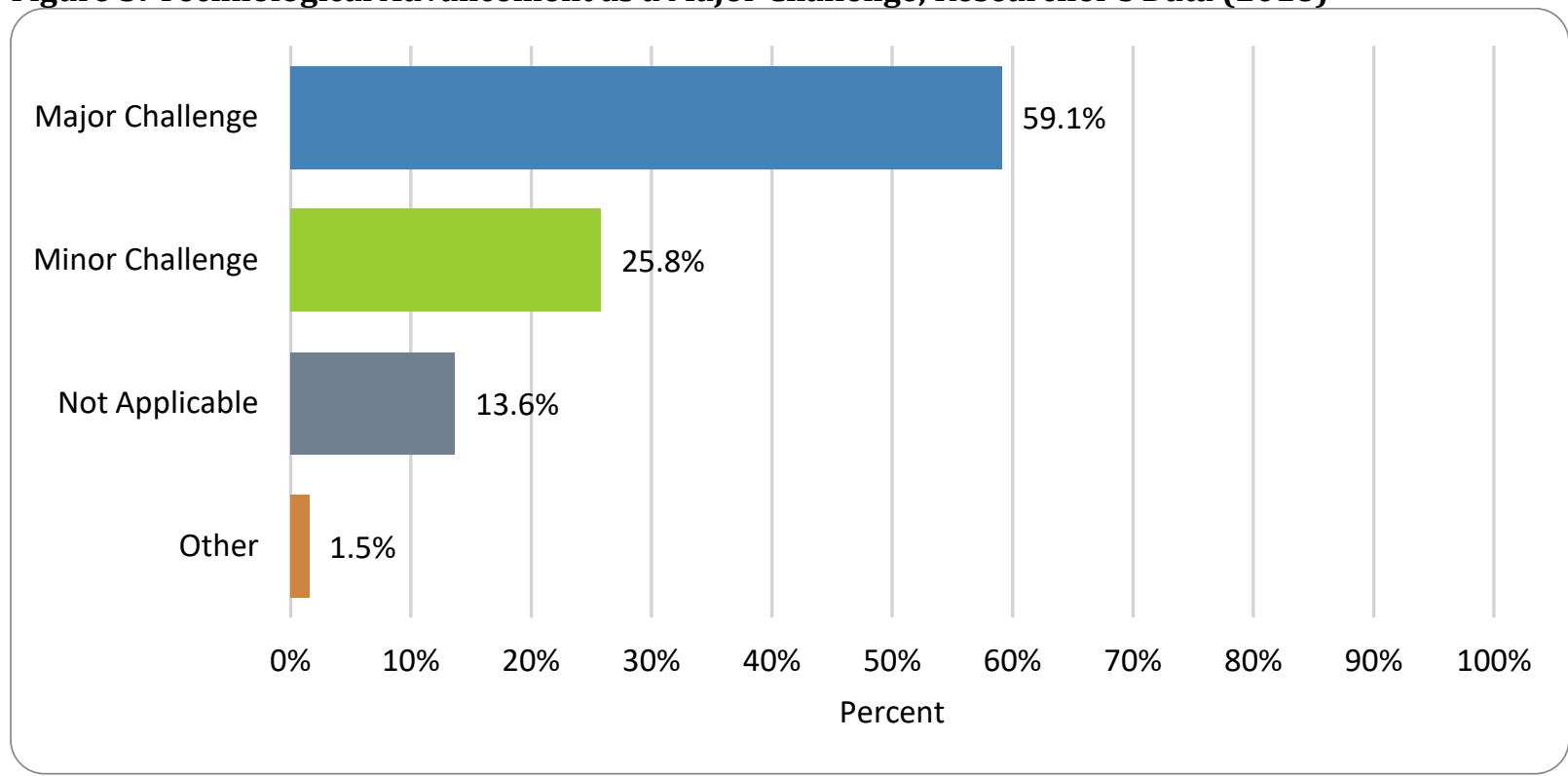

Figure 2 shows that $59.1 \%$ of the SMMEs in our survey identified technological advancements as a significant challenge. The respondents also understand the importance of technology and innovation, and advanced manufacturing approaches require high-tech machinery and equipment. These are critical drivers of manufacturing competitiveness. South African manufacturers are also slow in their adoption of technologyenabled interaction models within an industry 4.0 environment. A Deloitte study on Industry 4.0 agrees that South African manufacturers are slow in their adoption of technology-enabled interaction models in the industry 4.0 environment Deloitte (2016). Technological advances pose a challenge to SMMES due to the capital; many of the respondents were very aware of their limitations and mentioned that "The machines that we are using are basic electric machines.

Figure 4: Digital Manufacturing as a Major Challenge, Researcher's Data (2018), Digital Manufacturing as a Key Challenge for Manufacturing SMMEs in South Africa

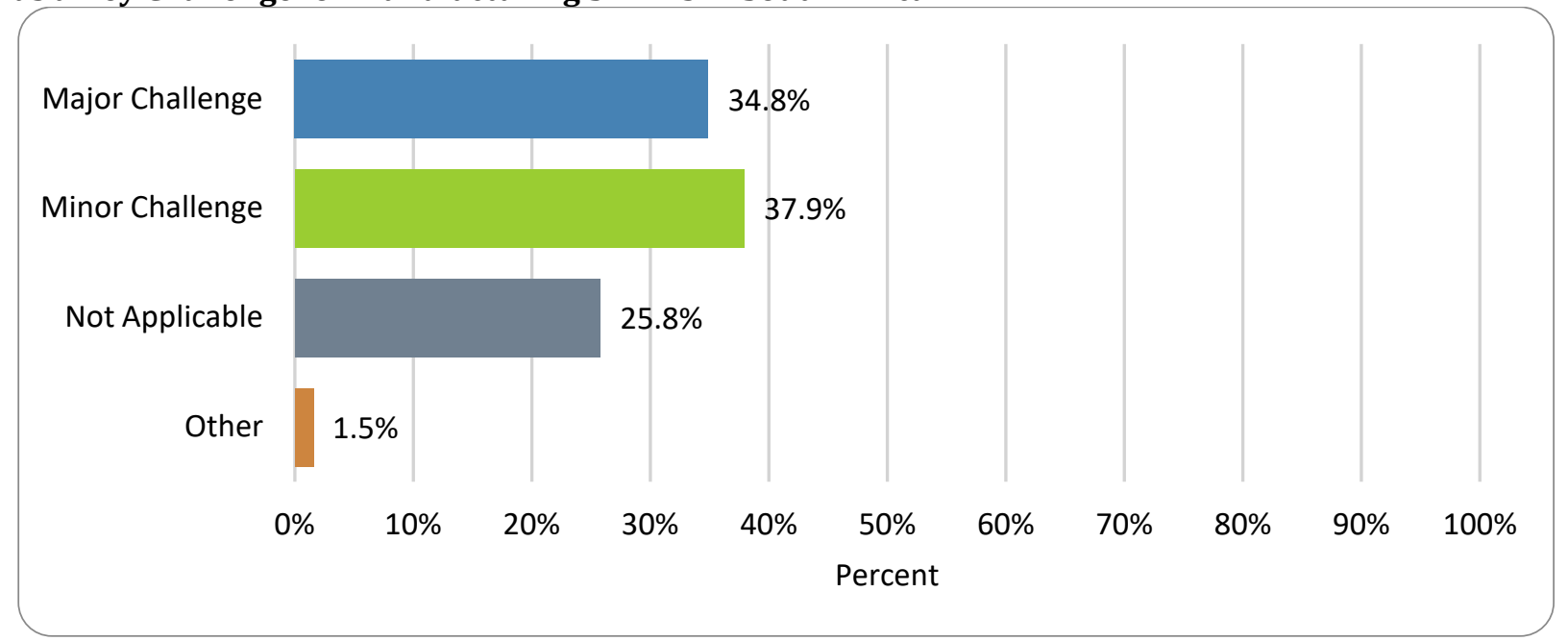

Digital technologies allow SMMEs to improve market intelligence and access global markets and knowledge networks at low costs. The Fourth Industrial revolution comes with the digital change that opens opportunities for SMMEs to scale up their business in a virtual setting without mass employees and other 
tangible assets this is evident in the prevalence of "lean start-ups". The respondent in this survey however still perceive Digital Manufacturing as a challenge; 34,8\% find it to be a major challenge, a slightly higher $37,9 \%$ find it to be a minor challenge. These SMMEs are not able to reap the benefits that come with the digital transition and are lagging. One of the respondents from the focus group discussions mentioned: "We need access to internet and Facebook. Respondent, (2018) Revealing a struggle with basic internet and connectivity. Soni et al. (2015) 's findings show that only 36\% of the surveyed SMMEs use computers for their business activities. One business owner emphasised that "He needs assistance with my company's digital presence"- (Respondent, 2018). This finding is corroborated by the SMMEs Quarterly Update Report from SEDA which states that "Faster and more affordable broadband access remains a tough nut to crack, but any progress in this regard will relieve one of the key infrastructure constraints in the economy." Seda, (2018:25). Reduced internet access costs and an expansion of internet coverage will go a long way in addressing South Africa's key infrastructure obstacles.

Discussion of Findings: Despite the continuing interventions SMMEs in the manufacturing still face challenges that threaten their growth and ability to participate in the fourth industrial revolution. The critical problem as discussed in this paper is the slow move to technological advancements and digital manufacturing. The results reveal that SMMEs still practising in the early phases of the Third Industrial Revolution. The findings show the poor infrastructure is holding SMMEs back and that more need to be done in increasing access to essential internet services and more financial support is necessary to assist SMMEs to acquire the latest automated machinery. An urgent and concerted effort is required to change this trajectory, hence the recommendations below.

\section{Conclusion and Recommendations}

There are several ongoing programmes and interventions focused on preparing and supporting South African SMMEs for the fourth industrial revolutions. One such programme is the Seda's Technology Transfer, and Innovation Programme has supported over 180 SMMEs from 2015/16 to 2018/19. The Seda Technology Transfer and Innovation Programme (Stp) provides a range of services that promote entrepreneurship in industry, particularly in enabling small enterprises to access appropriate technology to become more competitive and grow their businesses. The services include Technology Business Incubation, Quality Systems and Conformity Standards, Technology Transfer and Innovation Support. The Technology Transfer and Innovation Unit of Stp promotes and facilitates the transfer of industrially-relevant technologies and innovations, which are cost-effective, productive and competitive. Based on the results from this study it is clear that such programs are needed and can help SMMEs overcome their current challenges (Seda, 2018). From the onset Schwab, (2015), advocates for an integrated and comprehensive approach involving all stakeholders of the global polity including the public and private sectors, academia and civil society. This study recommends that this be the critical approach in preparing South Africa's SMMEs for the Fourth Industrial Revolution. The research shared an extensive literature review highlighting that SMMEs views on Technological Advancement and Digital Manufacturing as significant challenges.

An in-depth analysis of the survey results was provided, and based on those finding this section puts forward recommendations towards addressing these challenges. The fourth industrial revolution comes with a growing recognition of the role of knowledge and technology in economic growth. This has resulted in more investment directed toward high-technology sectors especially communications technologies, particularly in developed countries. South Africa should follow suit and increase investment in its manufacturing SMMEs. In addition to increased investment in existing manufacturing SMMEs, this study recommends for a preparation of future skills needs by the sector. The fourth industrial revolution is fast bringing about change in the world of work. As a result, Education and Training Institutions need to lead the way towards innovation and advancement by conduction long-term and short term research to keep ahead on the changes that are continuously introduced by Industry 4.0. The nature of work will be disrupted; there is a need to align the education system and the curriculum to the Fourth Industrial Revolution, focusing on high-skills and technical skill that will continue to be needed in manufacturing. Manufacturing firms globally emphasise the importance of talent-driven innovation and continue to work to update their equipment and technology. For this, they will require advanced skills. The education system should begin to educate learners and prepare them for future jobs. 
Manufacturing SMMEs need to now more than ever use this opportunity to scale-up, embrace new business and adapt quickly by embracing digitisation, computerisations, robotics and advanced technology throughout their business operations. In how they produce, what they produce and how they sell the products and interact with customers. The insertion of the Fourth Industrial Revolution into the education system to react to future skills needs and increased focus on manufacturing SMMEs as beneficiaries for government Business Development Support. Opportunities exist for SMMEs to develop new markets. However, poor infrastructure is holding many SMMEs back. A vital role from the government is critical here; acquiring the necessary infrastructure development and maintenance is essential. The government and all the relevant agencies supporting SMMES should be the driving force towards placing SMMEs in the centre of the Fourth Industrial Revolution; by firming up the attempt to increase access to technology, improving smart supply chain, and establishing government-led standards or good practice principles for technology development. This paper recommends addressing these challenges to place South Africa's manufacturing SMMEs at the centre of the Fourth Industrial Revolution to improve global competitiveness, grow the economy and create jobs through a complete overhaul of the education system. The study also recommends a change regarding the approach followed in addressing these issues. The study strongly recommends a collaborative approach that is inclusive of all relevant stakeholders. This will play a critical role in ensuring the successful implementation of required solutions.

\section{References}

Cohen, C. B. (2018). Industry 4.0: Are You Ready for the Fourth Industrial Revolution?

Deloitte (2016). Is industry 4.0-Is Africa ready for digital transformation? , s.l.: s.n.

Evans Distribution Systems. (2015). The Supply Chain Talent Drought.

Foresight (2013). The Future of Manufacturing: A New Era of Opportunity and Challenge for the UK Summary Report, London: The Government Office for Science.

Issa, A., Lucke, D. \& Bauernhansl, T. (2017). Mobilising SMEs towards Industrie 4.0-enabled Smart Products. Procedia, 63, 670-674.

Kearney, A. T. (2017). Technology and Innovation for the Future of Production: Accelerating Value Creation, Geneva: World Economic Forum.

Lee, M. Yun, J. H., Pyka, A., Won, D., Kodama, F., Schiuma, G., Park, H., John, J., Park, K., Jung, K., Yan, M., Lee, A. Y. \& Zhao, X. (2018). How to Respond to the Fourth Industrial Revolution or the Second Information Technology Revolution? Dynamic New Combinations between Technology, Market and Society through Open Innovation. Journal of Open Innovation: technology, Market, and Complexity, 4(21), 124.

Lu, Y. (2017). Industry 4.0: A survey on technologies, applications and open research issues. Journal of Industrial Information Integration, Issue 6.

Mutoko, W. (2014). Challenges of Access to Markets and Opportunities for Small, Medium and Micro Enterprises (SMMEs) in Botswana. European Scientific Journal, Volume Special Edition, 28-38.

Nieman, G. (2006). Small Business Management: A South African Approach. Pretoria: Van Schaik Publishers.

Respondent (2018). Manufacturing Support Programme Survey [Interview] (March 2018).

Schwab, K. (2015). The Fourth Industrial Revolution: What It Means and How to Respond.

Seda (2012). Research on the Performance of the Manufacturing Sector.

Seda (2018). SMME Quarterly Update: 3rd Quarter of 2017, Pretoria: SEDA.

Siyanbola, T. (2015). Challenges to the Growth and Development of Manufacturing and Services. Harvard, USA, The West East Institute, 186-199.

Slusarczy, B. (2018). Industry 4.0-Are We ready?. Polish Journal of Management Studies, 17(1), 232-246.

Soni, P., Cowden, R. \& Karodia, A. M. (2015). Investigating the characteristics and challenges of SMMEs in the Ethekwini Metropolitan Municipality. Arabian Journal of Business and Management Review, 3(10), 16.

Statistics South Africa. (2019). Manufacturing: winners and losers 2018, Pretoria: StatsSA.

StatsSA. (2017). Quarterly Report, Pretoria: Statistics South Africa.

Storck, C., Calandro, E. \& Gamage, R. (2013). The Future of Broadband in Africa, s.l.: Research ICT Africa.

World Economic Forum. (2017.) Technology and Innovation for the Future of Production: Accelerating Value Creation, Geneva: WEF.

Xu, M., David, J. M. \& Kim. S. H. (2018). The Fourth Industrial Revolution: Opportunities and Challenges. International Journal of Financial Research, 9(2), 90-95. 